\title{
An Exploratory Study of Length and Frequency of Internet Banking Usage
}

\author{
Booi Hon $\mathrm{Kam}^{1}$ and Hernan Riquelme ${ }^{2}$ \\ ${ }^{1}$ Royal Melbourne Institute of technology, School of Management, booi.kam@rmit.edu.au \\ ${ }^{2}$ Kuwait Maastricht Business School, Hernan@kmbs.edu.kw
}

Received 14 December 2006; received in revised form 02 February 2007; accepted 27 February 2007

\begin{abstract}
The advent of Internet has provided banks an opportunity to reduce costs, increase customer base, and mass customize by delivering their products and services through this medium. A flurry of studies on Internet banking (IB) has since emerged. The majority of these studies, however, have been directed to either IB adoption or IB service quality delivery. With few exceptions, the impact that customer satisfaction with e-banking service qualities has on IB usage remains unexplored. This study examines a sample of Australian IB users based on their frequency and length of usage. The results show that as customers become more acclimatized to IB, they use these services more often. Further, daily and frequent IB users are more pleased with "ease of use" and "aesthetics" and tend to use IB more for electronic fund transfer and foreign exchange transactions than the less frequent users. The findings suggest that banks need to develop more customized services since there are distinct market segments with different banking requirements.
\end{abstract}

Key words: Internet banking, e-business, online banking. 


\section{Introduction}

Although the dot.com debacle has held back electronic commerce in general, financial institutions continue to press hard to move offline users online [3]. This is no surprise since nearly three times as many online households in the United States cite financial transactions as one of the most important reasons for using the Internet than those who mention purchasing products [17]. Another reason is that by using the Internet as a communication and delivery medium, banks can integrate their services to reach far more clients without the limitations of physically located delivery systems, like branches or ATMs, making it easier to cross-sell products as well as achieving scale economies. In turn, this has enabled many banks to offer competitive rates in bill payment, brokerage services, and stock market transactions [12]. Claessens et al. [9], for instance, estimated banks could lower their transaction costs from about US\$1.00 for a branch transaction to US $\$ 0.20$ for an Internet transaction. De Young [12] reports a broader difference still: US\$1.07 per transaction in a branch compared with US\$0.01 on the Internet.

Notwithstanding the "push" efforts made by banks, less than $56 \%$ of Internet users in the United States conduct online banking compared with more than $63 \%$ who carry out online purchasing [17]. The need to understand the behavioral underpinnings of internet banking (IB) adoption has resulted in attempts being made to apply some of the seminal technology adoption theories, such as (TPB) Theory of Planned Behaviour [1], (TRA) Theory of Reasoned Action [13], (TAM) Technology Acceptance Model [11]; (TAM2) [29], Social Cognitive Theory [2], and Theory of Diffusion of Innovations [27], to examine the determinants of IB adoption among consumers in different cultures (see for example [4], [6], [15], [28]).

Apart from IB adoption, research on IB has been directed toward IB service quality delivery. Some of these works include Jun and Cai [18], Joseph et al.[19], Joseph and Stone [20], and Patricio et al.[25]. With few exceptions (such as [7], [14], [26]), little is known about the impact customer satisfaction with e-banking service quality has on IB usage. This study aims to empirically assess the effects, including the manner in which, as well as the extent to which, satisfaction toward different e-banking service quality dimensions have on IB usage, both in terms of length of adoption as well as frequency of use. Specifically, this study will explore five key issues relating to IB usage:

1. Is there any correlation between length and frequency of IB use?

2. Does satisfaction with any particular e-banking service quality dimensions lead to higher IB usage?

3. Does length of IB usage necessarily imply a higher level of satisfaction with any particular e-banking service quality dimensions?

4. Is length of IB adoption or frequency of IB use associated with any particular types of IB activities?

\section{Adoption of and Satisfaction with e-Banking Service Quality}

Chan and Lu [6], who applied TPB, TAM and TAM2 theories to examine IB adoption in Hong Kong, concluded that intention to continue to use IB is influenced directly by perceived usefulness, perceived ease of use of the medium, and subjective norms. Perceived usefulness, in turn, is influenced by image and result demonstrability, while perceived ease of use is affected by computer self-efficacy (user's own competence). An earlier study by Tan and Teo [28], however, found the following variables predicted IB adoption in Singapore: relative advantage, compatibility, Internet experience, banking needs, trialability, risk, self-efficacy, and government support. Brown et al.[4], who carried out a similar study in South Africa, however, revealed that compatibility, trialability, and self-efficacy were the key determinants of IB adoption. Yet, a later study between adopters and non-adopters in Singapore discovered that innovativeness, compatibility, PC competence, and complexity were distinguishing factors that influence adoption of e-banking [15]. These disparate findings suggest that IB adoption is a function of a complex host of factors, some of which could be time and context specific.

As for research on IB service quality delivery, the focus has been on identifying service quality dimensions and measuring consumer's perceived performance of these dimensions. The former is generally referred to as a global judgment or attitude, implying some superiority of a service [24], while the latter is usually defined as the post-purchase evaluation of overall product or service experience over time [8], [21].

In general, there is sufficient empirical support indicating that service quality, if not a major determinant, does exert a positive and strong influence on consumer satisfaction [5],[10],[22],[24],[31]. However, these service quality dimensions do seem to vary according to users' cultural environment and demographics. Joseph et al.[19], for instance, in their study

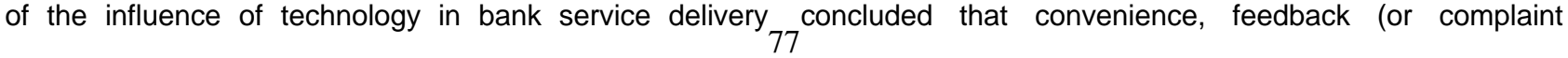


management), efficiency, queue management, accessibility, and customization were of importance. These findings coincide with those of Polatoglu and Ekin [26], who found that IB users in Turkey see main advantages in transacting online because of accessibility, time saving, ease of use, and feedback control.

On the other hand, Patricio et al.[25], based on a sample of Spanish users, unearthed security concerns and lack of information quality, followed by unavailability of functions, as the most common factors inhibiting IB use. A survey [20] asking consumers to evaluate bank channel delivery services - ATM, Internet, and telephone banking - found that accuracy is the most important service quality attribute, followed by security, accessibility, convenience, and confidence in the bank. These dimensions were found to differ according to gender and age with the differences concentrated in strength rather than in direction. In other words, it is not that one group disagrees with the level of importance attached to different attributes and the other agrees. It is that females attach a higher perceived importance than do males to some dimensions, such as "have all my banking needs included in the menu options", "greet me by using my name", "be able to set up accounts so that I can perform transactions immediately". Furthermore, respondents aged 41 and above considered the following categories more important than respondents between 18 and 40 years of age: convenient location, wide range of electronic services, efficiency, established customer feedback system, complaint management, special services, and access to online directions.

Analyzing critical incidents posted in the www.Gomez.com web site, Jun and Cai [18] inferred that consumers rely on 17 dimensions to qualify internet service quality. Based on mentioned frequency, they concluded that the following dimensions were the most important to online system quality, accounting for $77 \%$ of total frequency: content, accuracy, ease of use, timeliness, aesthetics, and security. From these dimensions, it may be inferred that online banking users rely on online system quality dimensions more so than other banking-specific categories, although there is consistent claim that consumers expect a wide range of services and products from a bank and would like to conduct a series of transactions [20]. Chung and Paynter [7] adapted Hersey' web site evaluation instrument to measure the performance of seven banks in New Zealand in relation to the presence or absence of variables, such as information provided on the web site, legal statement, ease of use, and aesthetics effects. To determine the importance of the different variables from a customer perspective, Chung and Paynter [7] conducted a survey among users and non users of internet banking. Seventy five IB users ( $41 \%$ of the sample) indicated secure transaction, followed by up-to date information and free from technical problem (reliability) as the three most important factors. The most commonly cited factor for not registering for IB is security transaction, followed by the availability of alternative channels and lack of trial. In a different survey published by ForeSeeResults.com [14], privacy surfaced as the most significant deterrent to online registration.

In terms of consumer satisfaction with online banking service qualities, most studies have found positive reactions from respondents regarding their IB services. A survey conducted in 2004 by ForeSeeResults.com [14] of online and offline banking customers, for instance, found that online consumers score high (77 out of 100 points on the American Customer Satisfaction Index) on level of satisfaction, with ease of navigation and transactions as the key drivers of their satisfaction. Joseph and Stone [20] reported that $77 \%$ of the respondents were satisfied with their overall IB experience, and Zineldin [29] found that customers, in general, were very pleased with online banking in Sweden, particularly with ForeningsSparbanken (FSB). This is also true in the U.S.A. according to a survey conducted by ForeSeeResults in conjunction with Forbes.com [23]. These results are encouraging when compared with a study conducted by the Gartner Group in 2000 [30], reporting that one third of customers who tried banking online gave it up later.

Despite the positive findings regarding consumers' attitudes toward IB service qualities, little is known of the consequences of such positivism, i.e., whether high levels of satisfaction do translate into higher level of IB usage. It is possible that satisfaction with IB service qualities may only represent a necessary, but not sufficient, condition toward usage frequency and continuity. Williams' [30] comment that to attract customers, banks will have to offer much more than just the ability to transfer funds, check balances, or pay bills, is testimonial to this proposition. Few studies have delved into the relationship between satisfaction and impact on other variables. Chung and Paynter [7] found that overall satisfaction with online banking leads to future usage and is correlated with use frequency of phone banking. ForeSeeResults.com's survey [14] concluded that satisfied customers use six or more online features than less satisfied clients. Online bank customers obtain most of their bank news from the banks' web sites, and use online facilities to pay bills and monitor account balances.

The present study attempts to further examine some of these consequences with a view to specifically explore the following relationships:

\section{1. between length of IB adoption and frequency of IB use}

2. between satisfaction with IB service qualities and frequency of IB use

3. between satisfaction with IB service qualities and length of IB adoption 
4. between frequency of IB use and types of IB activities engaged in

5. between length of IB adoption and types of IB activities engaged in

\section{Materials and Methods}

\subsection{Data and Profile of Respondents}

Data for this study came from a convenience sample of 203 respondents who had operated at least one IB account in Australia during the preceding four months prior to the survey. The questionnaire was placed online. Respondents were recruited using a snowball approach: friends and colleagues (of the researchers) meeting the IB account operation criterion were invited to respond to the survey online. In turn, they were also requested to persuade their friends and associates fitting the same criterion to participate in the online survey.

The questionnaire used comprises five main sections: general Internet usage, IB usage, usage frequency of IB services, satisfactions with IB service qualities, and demographics. IB service quality dimensions employed were based on those adopted by Jun and Cai [18]. Each dimension was rated on five-point scale: from "extremely dissatisfied" (1) to "extremely satisfied" (5). Types of IB activity engaged in were measured by frequency of use with respect to seven IB services: information enquiries (such as checking statement balance); money transfers (or electronic fund transfer); foreign exchange transaction; loan application (such as housing and/or personal loans); shares trading (i.e., buy/sell); making payments; and bank checks. Again, a five-point ordinal scale was used: from "never" (1) to "always" (5).

The sample comprises more female (57\%) than male. The majority of the respondents (77\%) were in the $25-44$ yearold category. Access to the Internet was mainly at work (59\%) or home (39\%). Over $84 \%$ had been using the Internet for banking purposes for more than two years, and over half use IB weekly or at least a few times a week. Over $56 \%$ of the respondents use more than one Internet bank in addition to other delivery channels: branch (63\%), phone (40\%), ATM (94\%), and kiosks (22\%).

\subsection{Method of Analysis}

To investigate how satisfaction toward e-banking service quality dimensions relates to IB usage, two usage variables were defined. The first variable measures users with respect to their frequency of IB use, which is accomplished by dividing respondents into five usage groups: daily, frequently (i.e., a few times a week), weekly, fortnightly, and occasionally. The second variable measures respondents according to the time they have been using IB services. Based on the terminology introduced by Rogers [27] for categorizing technology adopters, respondents were classified into three groups - Early Adopters (users who have been using IB services for more than 3 years), Late Adopters (users who have adopted the service between 18 and 36 months), and Laggards (users who have been using IB services for less than 18 months).

To address the research questions and relationships posed, a mix of statistical analyses was conducted, commencing with a simple profile analysis of the various groups of IB users to highlight the distinguishing demographic features and income level separating them. This is followed by a relational analysis of frequency of IB use and length of IB adoption to determine whether length of IB adoption would lead to a higher frequency of IB use over time. Finally, four stepwise discriminant analyses were performed, the group and predictor variables for each of which are as shown in Table 1 . The first two discriminant analyses used frequency of IB use as a group variable. E-banking service quality dimensions were the predictor variables for the first discriminant analysis, and types of IB activities, those for the second. In the third and fourth discriminant analyses, length of IB adoption was the group variable. Again, e-banking service quality dimensions and types of IB activities were the respective predictor variables for each. 


\begin{tabular}{|c|c|c|c|}
\hline & \multirow[t]{2}{*}{ Group Variable } & \multicolumn{2}{|l|}{ Predictor Variables } \\
\hline & & Set 1 & Set 2 \\
\hline 1 & $\begin{array}{l}\text { Frequency of Using } \\
\text { Internet Banking } \\
\text { Five Groups: } \\
\text { - Daily Users } \\
\text { - Frequent Users } \\
\text { (Few times per } \\
\text { week) } \\
\text { - Weekly Users } \\
\text { - Fortnightly Users } \\
\text { - Occasionally } \\
\text { Users (once per } \\
\text { month or less) }\end{array}$ & $\begin{array}{l}\text { Satisfaction Scores on } \mathbf{1 6} \text { service attributes } \\
\text { - Reliability - ability of my Internet bank to perform the } \\
\text { promised service dependably and accurately. } \\
\text { - Responsiveness - speed, timeliness and convenience of } \\
\text { Internet service delivery. } \\
\text { - Courtesy - communication with my bank is always polite, } \\
\text { respectful and prompt. } \\
\text { - Credibility - my Internet bank is trustworthy, believable } \\
\text { and honest. } \\
\text { - Access - my Internet bank is easily accessible. } \\
\text { Communication - my Internet bank keeps me informed of } \\
\text { information I need and in a format which I can easily } \\
\text { understand. }\end{array}$ & 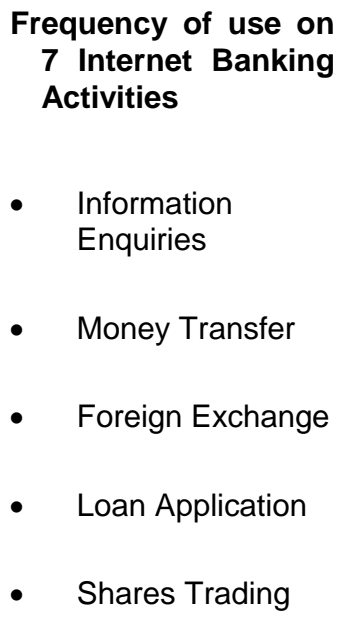 \\
\hline 2 & $\begin{array}{l}\text { Length of Using } \\
\text { Internet Banking } \\
\text { Three Groups: } \\
\text { - Laggards: less } \\
\text { than } 18 \text { months, } \\
\text { - Late Adopters: } 18 \\
\text { to } 36 \text { months, } \\
\text { - Early Adopters: } \\
\text { greater than } 36 \\
\text { months }\end{array}$ & $\begin{array}{l}\text { - Understanding - my bank makes an effort to know me and } \\
\text { understands my needs. } \\
\text { - Co-ordination between bank departments and their } \\
\text { employees to deliver a timely and reliable service. } \\
\text { - Co-ordination between Internet bank and its business } \\
\text { partners to deliver timely and reliable services to } \\
\text { customers. } \\
\text { - Content - all the information I need is on the Internet bank } \\
\text { website. } \\
\text { - Accuracy - the information provided on the Internet bank } \\
\text { website is free of error. } \\
\text { Ease of use - interacting with my bank via its website is } \\
\text { user friendly. } \\
\text { Timeliness - ability to access up-to-date information on my } \\
\text { Internet bank website. } \\
\text { - } \text { Aesthetics - attractiveness of the Internet bank website. } \\
\text { Security - online transaction safety and privacy. } \\
\text { Product variety/features -width of product range and } \\
\text { variety of product features available via the Internet } \\
\text { banking website. }\end{array}$ & $\begin{array}{l}\text { - } \quad \text { Payments } \\
\text { - } \quad \text { Bank Check }\end{array}$ \\
\hline
\end{tabular}

Table 1: Group and Predictor Variables used in Discriminant Analysis 


\section{Results}

\subsection{Demographic Profile of IB Users}

The demographic profile of the five user groups, based on their frequency of IB use, shows that Occasional and Fortnightly Users are predominantly male aged between 35 and 54, with the former more aligned with those in the older 45 to 54 year old cohort and the latter in the younger 35 to 44 cohort. The two groups also tend to be spread across a number of income groups. Daily Users are distinguished by their higher income (above $A \$ 80,000$ per annum) and most are in the 35 to 44 age category. Frequent Users are generally females less than 34 years of age, and have at least a technical qualification or have undergone undergraduate studies. While Weekly Users are also dominated by females, they are generally in the older age category of 45 to 54 years old and many have only secondary education.

By length of IB adoption, Early Adopters are characterized by male aged 35 to 44 with postgraduate qualifications and earning no less than $\mathrm{A} \$ 80,000$ annually. By contrast, Late Adopters are generally younger (25 - 34), with somewhat lesser education compared with Early Adopters and tend to be earning largely between $A \$ 30,000$ and $A \$ 70,000$ per annum. Laggards are predominantly those in either the younger age cohort of 18 to 24 years old or those between 45 and 54 years old.

\subsection{Length of IB Adoption and Frequency of IB Use}

A relational analysis of length of IB adoption and frequency of IB use suggests that the two are closely linked (see Figure 1). Almost $60 \%$ of Early Adopters use IB services daily and frequently. The corresponding figures for Late Adopters and Laggards are about $45 \%$ and less than $25 \%$. On the other hand, over $45 \%$ of Laggards use online banking services fortnightly or less, but only $25 \%$ and $20 \%$, respectively, of Late and Early Adopters use it at this frequency. This association between the two variables suggests that the longer IB users have embraced online banking, the more frequent they would be utilizing this service, other things being equal.

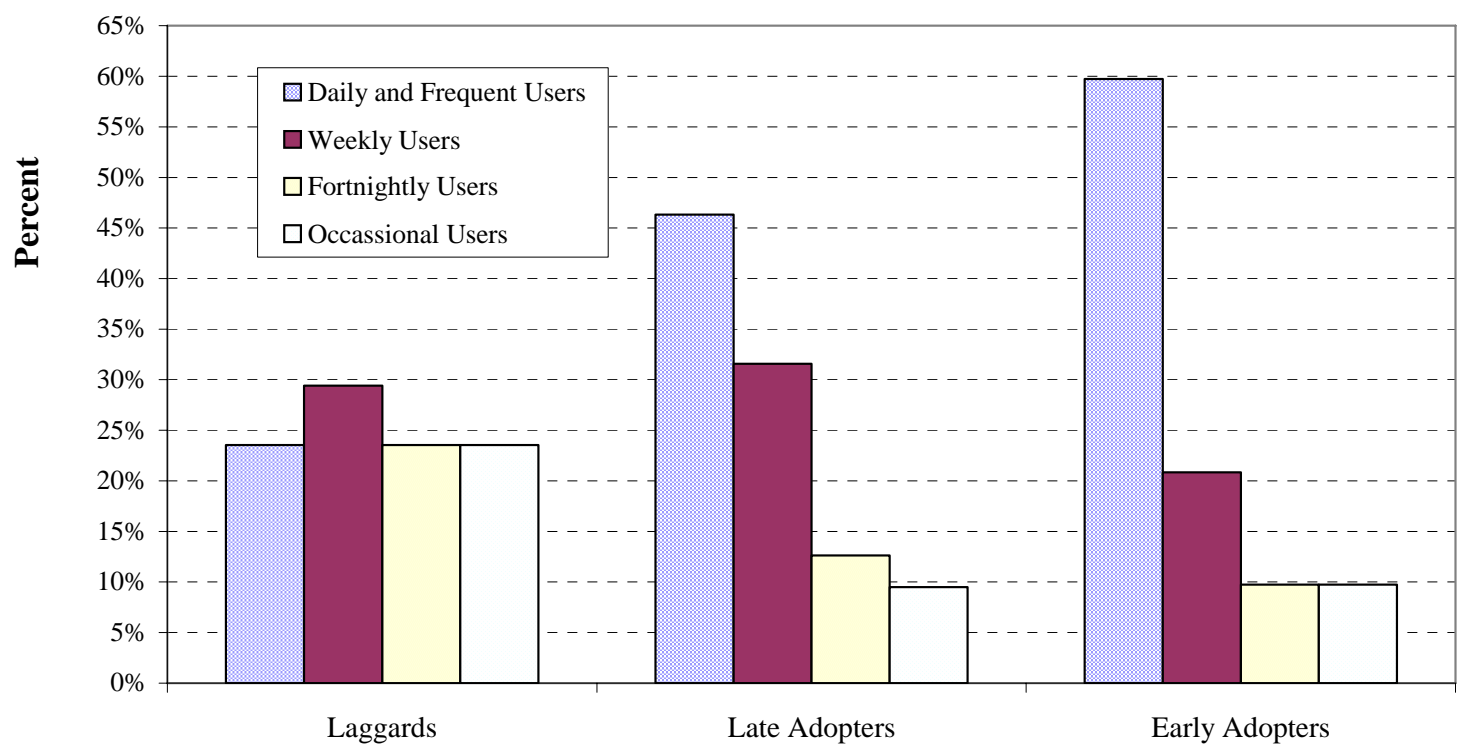

IB Users by Length of Adoption

Note: $\mathrm{A} \chi^{2}$-test on the cross-tab between length and frequency of IB use shows that the two are statistically significant at $\alpha=0.01$.

Figure 1: Frequency of IB Use by Length of IB Adoption 


\subsection{Factors Differentiating between Frequency and Length of IB Usage}

Using satisfaction ratings on the 16 IB service attributes to distinguish between frequency of usage, two of the attributes ease of use and aesthetics - were found to be statistically significant $(\alpha=0.1)$. From the relative loadings of these two attributes on the two resulting discriminant functions and the group centroids of the five frequency of use groups (see Figure 2), it is noted that Frequent Users are most satisfied with these two features. They find IB relatively user-friendly and regard IB websites as attractive. In comparison, Weekly Users generally find IB less easy to use and are also less impressed with the design of IB websites. The same may also be said of Fortnightly Users, though their level of dissatisfaction is less intense compared with Weekly Users. Daily Users are relatively pleased with the aesthetics of the IB websites but do not find IB as easy to use as Frequent Users. Occasional Users, on the other hand, do not consider IB use as easy and satisfactory, compared with their more frequent counterparts, but are somewhat pleased with the aesthetic features of IB websites.

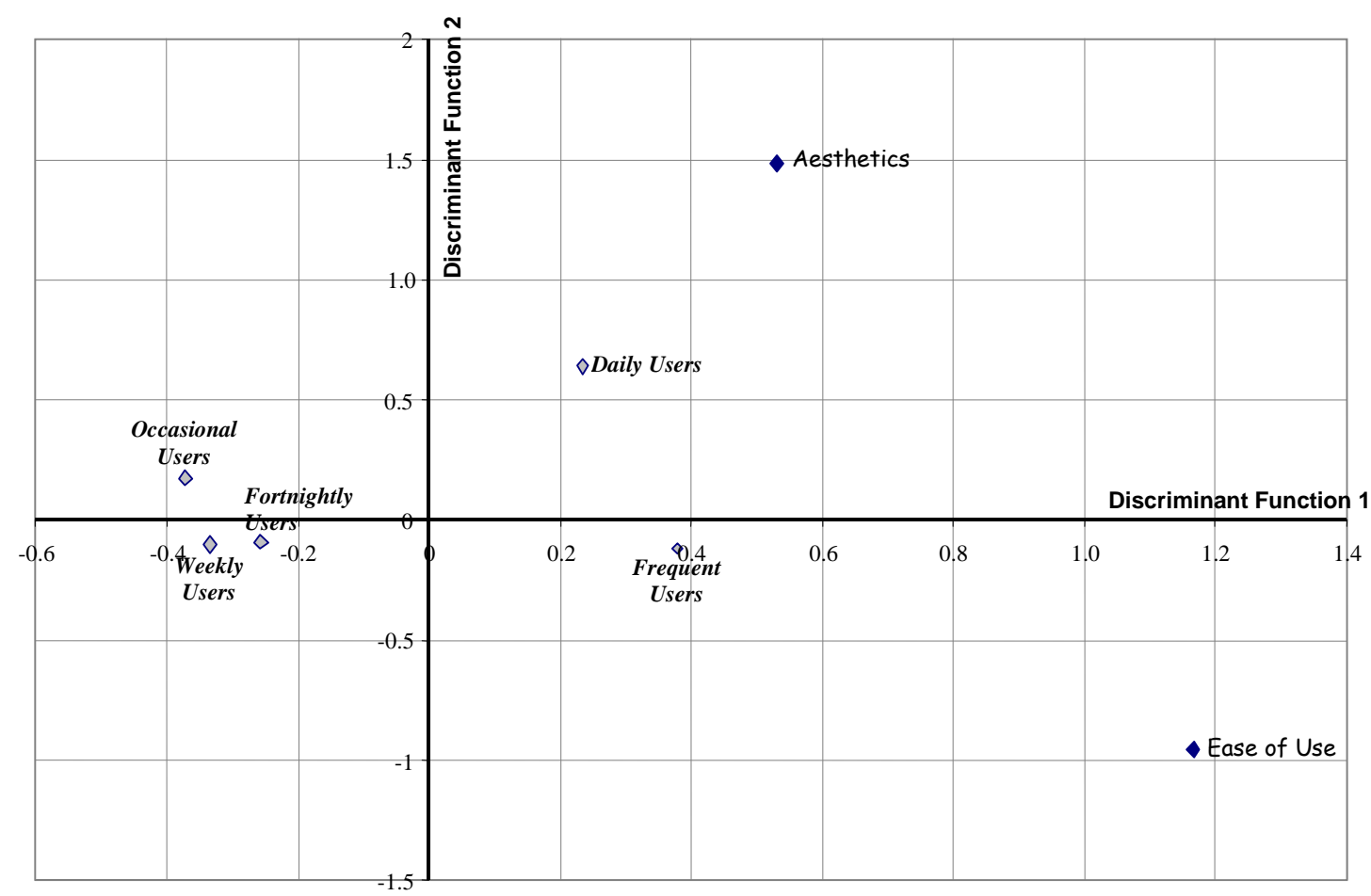

Note: The two variables - ease of use and aesthetics - defining the two discriminant functions are significant at the $\alpha=0.10$ level.

Figure 2: Plot of Satisfaction Scores and Centroids of User Groups by Frequency of IB Use in Discriminant Space

Discriminating frequency of IB use by the relative frequency of IB activities carried out, information enquiries, electronic fund transfer, and foreign exchange trading surfaced as statistically significant $(\alpha=0.05)$ (see Figure 3$)$. Compared to other users, Daily Users generally use IB more often for all three purposes, especially foreign exchange and information enquiries. The other four user groups do tend to use IB more for information enquiries than the other two purposes. Among them, Occasional Users are least inclined to engage in any of these IB activities.

No statistically significant predictor variables were identified when length of IB adoption was discriminated with satisfaction scores on the 16 e-banking service quality attributes. When the predictor variables were changed to types of IB activity, two variables - share trading and bill payment - emerged as significant $(\alpha=0.05)$. From the two discriminant functions defined by these two variables (see Figure 4), it is noted that Early Adopters tend to use IB for these two activities more often than either Late Adopters or Laggards. Both Late Adopters and Laggards seem to use IB more for paying bills than share trading, though Late Adopters generally have a higher level of usage intensity for these two activities than Laggards. 


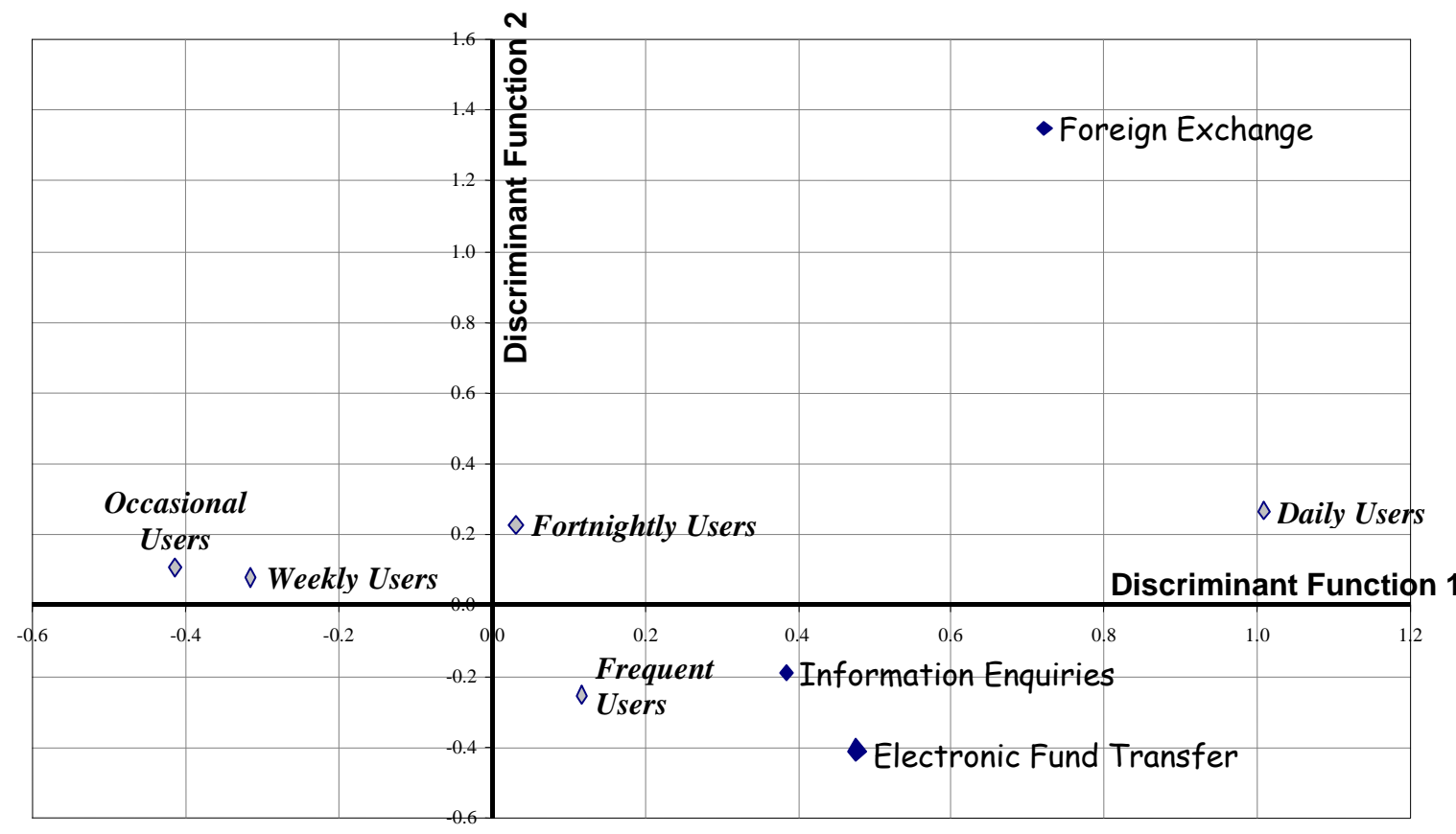

Note: All three variables - foreign exchange, information enquiries, and electronic fund transfer - defining the two discriminant functions are significant at the $\alpha=0.05$ level.

Figure 3: Plot of IB Activities and Centroids of User Groups by Frequency of IB Use in Discriminant Space

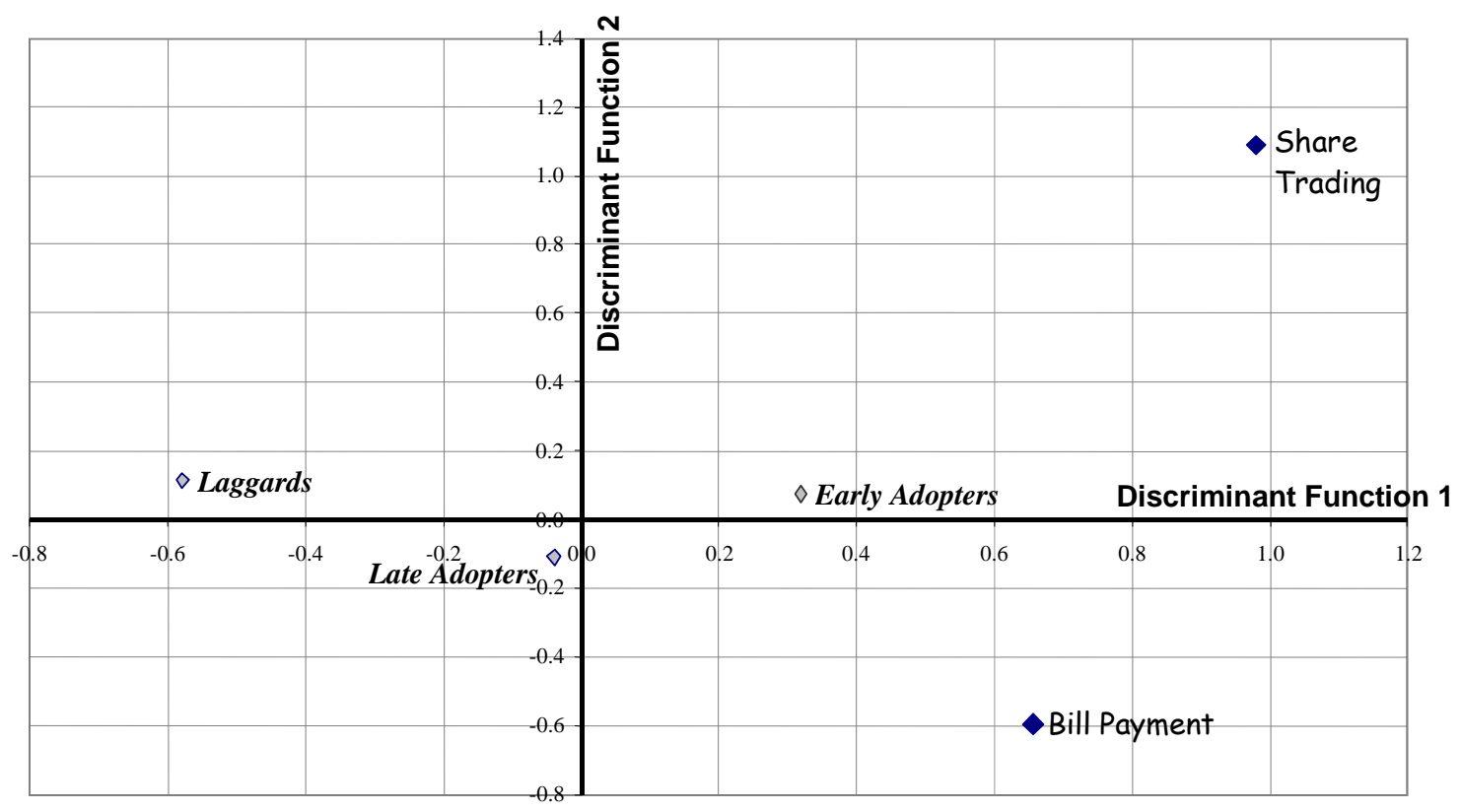

Note: The two variables - share trading and bill payment - defining the two discriminant functions are significant at the $=0.05$ level.

Figure 4: Plot of IB Activities and Centroids of User Groups by Length of IB Use in Discriminant Space 


\section{Interpretation of Findings and Marketing Implications}

In response to the key research issues posed, the results of the statistical analyses have shown that:

1. There is a close association between length of IB adoption and frequency of IB use, suggesting that as users get acclimatized with the online environment, they would tend to use IB services more often.

2. Among the five frequencies of IB use groups, Occasional Users have the most adverse reaction to the "ease of use" feature of IB. All things being equal, this might be one of the prime reasons deterring Occasional Users from engaging in IB activities.

3. In comparative terms, Daily and Frequent IB users are more pleased with two of the e-banking service quality features - ease of use and aesthetics - than their less frequent counterparts. These two groups of users also have a higher inclination to use IB for information enquiries and electronic fund transfer than the other three groups of less frequent users. In addition, Daily Users also have the highest propensity to use online banking services for foreign exchange.

4. By length of IB adoption, there appears to be a distinct decline in share trading and bill payment activities as the history of IB adoption shortens. Early Adopters tend to use IB for these purposes more often than Late Adopters and Laggards.

Taken together, the above findings suggest that frequency of IB use is linked to diversity and complexity of IB usage. The negative perception that IB may not be easy to use among the infrequent and occasional users remains a major hurdle prompting greater use of online banking services among recent adopters. While the findings do suggest that over time, such a muted perception may change to become an upbeat one, the pace of transformation is a cost burden that banks can do without, given the wide service cost chasm between online and offline transactions.

From a bank marketing perspective, therefore, it may not be a question of how to implement more user-friendly features, but more so an issue of how to assure and demonstrate to consumers that IB is easy to use. Because aesthetics is also a significant attribute distinguishing the regular and more frequent users from the infrequent and occasional users, increasing the attractiveness of banks' websites, especially on features supporting information enquiries, may be the first step toward instilling an "easy" feeling among the latter, prompting them to use IB more often in the first instance, and, over time, to use IB for purposes other than information seeking.

On a less obvious front, the inability of the stepwise discriminant analyses to pick up more significant predictor variables from the 16 service attributes that have been tested by Jun and Cai [18] suggests that IB, to an extent, has reached a level of maturity where the quality of many service attributes, including security, no longer stands out as a differentiator of customer satisfaction. Regardless of the length and frequency of IB usage, there is relatively little difference between the satisfaction levels of regular and occasional users and between those of early adopters and laggards. This less noticeable finding implies that banks may need to consider developing more customized and allied services associated with online banking. Creating value for clients by providing complementary products would certainly be an option, as Hadden and Whalley [16] have discovered: bank clients, when describing their thoughts about a house mortgage, consider everything about their new home, including mortgage products, local solicitors, community information, and home decoration. At a stage when IB users are already relatively satisfied with most dimensions of e-banking service quality, complementary products might feature more importantly in inducing a higher level of IB usage. Product and service customization may have to be the central trait among the next wave of marketing initiatives employed by banks to entice offline users to bank online.

\section{References}

[1] I. Ajzen, From intentions to actions: a theory of planned behavior, in Action Control: From Cognition to Behavior, (J. Kuhl and J. Beckmann, Eds.). New York, NY: Springer- Verlag, 1985, pp.11-39.

[2] A. Bandura, Self-efficacy mechanisms in human agency, American Psychologist, vol. 37, pp. 122-147, 1982.

[3] J. Boughin, E-push or e-pull? Laggards and first-movers in European online banking, Journal of Computer Mediated Communication, vol. 7, no. 1, 2001.

[4] I. Brown, R. Hoppe, P. Mugera, P. Newman, A. Stander, The impact of national environment on the adoption of internet banking: Comparing Singapore and South Africa, Journal of Global Information Management, vol. 12, no. 2, pp. 1-26, 2004.

[5] A. Caruana, Service loyalty: the effects of service quality and the mediating role of customer satisfaction, European 
Journal of Marketing, vol. 36, no. 7/8, pp. 811-828, 2002.

[6] S. C. Chan and M. T. Lu, Understanding internet banking adoption and use behavior: A Hong Kong perspective, Journal of Global Information Management, vol. 12, no. 3, pp. 21-43, 2004.

[7] W. Chung and J. Paynter, An evaluation of Internet banking in New Zealand, in Proceedings of the 35th Annual Hawaii International Conference on Systems Sciences, Hawaii, 2003, pp. 2410-2419.

[8] J. G. A. Churchill and C. Suprenant, An investigation into the determinants of customer satisfaction, Journal of Marketing Research, vol. 19, pp. 481-504, 1982.

[9] S. Classens, T. Glaessner, and D. Klingebiel, Electronic finance: Reshaping the financial landscape around the world, Journal of Financial Services Research, vol. 22, no. 1/2, pp. 29-61, 2002.

[10] J. Cronin, M. Brady, and T. Hult, Assessing the effects of quality, value, and customer satisfaction on consumer behavioral intentions in service environments, Journal of Retailing, vol. 76, no. 2, pp. 193-218, 2000.

[11] F. D. Davis, R.P. Bagozzi, and P.R. Warshaw, User acceptance of computer technology: a comparison of two theoretical models, Management Science, vol. 35, no. 8, pp. 982-1003, 1989.

[12] R. de Young, The financial performance of pure play Internet banks, in Economic Perspectives, Federal Reserve Bank of Chicago, 2001, pp. 60-75.

[13] M. Fishbein and I. Ajzen, Belief, Attitude, Intention and Behavior: An Introduction to Theory and Research. Reading, MA: Addison Wesley, 1975.

[14] ForeSeeResults (2005, Winter). Online banking: Customer satisfaction and its implications for building loyalty and influencing buying behavior. [Online]. Available: $\underline{\text { http://foreseeresults.com/Form 2005OnlineBanking.html. }}$.

[15] P. Gerrard and J.B. Cunningham, The diffusion of Internet banking among Singapore consumers, International Journal of Bank Marketing, vol. 21, no. 1, pp. 16-28, 2003.

[16] R. Hadden and A. Whalley, The branch is dead, long live the Internet! (or so you'd have thought if we had not listened to the customer), International Journal of Market Research, vol. 44, no. 3, pp. 283-297, 2002.

[17] D. Hallerman. (2005, October). Online Banking Customers: Attitudes and Activities [Online]. Available: http://www.emarketer.com/Reports/All/Banking on nov05.aspx?src=report head info sitesearch.

[18] M. Jun and S. Cai, The key determinants of Internet banking service quality: A content analysis, International Journal of Bank Marketing, vol. 19, no. 7, pp. 276-291, 2001.

[19] M. Joseph, C. McClure, and B. Joseph, Service quality in the banking sector: The impact of technology on service delivery, International Journal of Bank Marketing, vol. 17, no. 4, pp. 182-191, 1999.

[20] M. Joseph and G. Stone, An empirical evaluation of US bank customer perceptions of the impact of technology on service delivery in the banking sector, International Journal of Retail and Distribution Management, vol. 31, no. 4, pp. 190-202, 2003.

[21] C.H. Lovelock, P.G. Patterson and R. Walker, Services Marketing. 2nd ed. Frenchs Forest, NSW: Pearson Education, 2001.

[22] S. Olsen, Comparative evaluation and the relationship between quality, satisfaction and repurchase loyalty, Journal of the Academy Marketing Science, vol. 30, no. 3, pp. 240-249, 2002.

[23] B. Orr, E-banking job one: Give customers a good ride, American Bankers Association Journal, vol. 96, no. 5, pp. 56-57, 2004.

[24] A. Parasuraman, V.A. Zeithaml, and L.L. Berry, SERVQUAL; A multi item scale from measuring consumer perceptions of service quality, Journal of Retailing, vol. 64, pp. 12-40, 1988.

[25] L. Patricio, R.P. Fisk, and J. Falcão e Cunha, Improving satisfaction with bank service offerings: Measuring the contribution of each delivery channel, Managing Service Quality, vol. 13, no. 6, pp. 471-482, 2003.

[26] V. N. Polataglu, and S. Ekin, An empirical investigation of the Turkish consumers' aceptance of Internet banking services, International Journal of Bank Marketing, vol. 19, pp. 4-17, 2001.

[27] E. M. Rogers, Diffusion of Innovations. New York, NY: Free Press, 1983.

[28] M. Tan and T. S. H. Teo, Factors influencing the adoption of internet banking, Journal of the Association for Information Systems, vol. 1, no. 5, pp. 1-44, 2000.

[29] V. Venkatesh and F. D. Davis, A theoretical extension of the technology acceptance model: Four longitudinal field studies, Management Science, vol. 46, pp. 186-204, 2000.

[30] K. Williams, Are you ready for Internet banking? Strategic Finance, vol. 81, no. 10, pp. 23 \& 82, 2000

[31] V. A. Zeithaml, L. L. Berry, and A. Parasuraman, The behavioural consequences of service quality, Journal of Marketing vol. 60, pp. 31-46, 1996.

[32] M. Zineldin, Managing in the @ age: Banking service quality and strategic positioning, Measuring Business Excellence, vol. 6, no. 4, pp. 38-43, 2002. 